\title{
Learners' Experiences in a Multicultural Remote Collaborative Learning Environment: A case of ICT4D Course
}

\author{
Elizaphan Maina ${ }^{1}$, Nicholas Mavengere ${ }^{2}$, Francis Manzira ${ }^{3}$, John kihoro ${ }^{4}$, \\ Mikko Ruohonen ${ }^{5}$ \\ ${ }^{1}$ Kenyatta University, Kenya \\ maina.elizaphan@ku.ac.ke \\ ${ }^{2}$ University of Tampere, Finland \\ Nicholas . Mavengere@staff . uta.fi \\ ${ }^{3}$ University of Venda, South Africa \\ mfmanzira@gmail.com \\ ${ }^{4}$ The Cooperative University of Kenya \\ Kenya, kihoro.jm@cuck.ac.ke \\ ${ }^{5}$ University of Tampere, Finland \\ mikko.ruohonen@uta.fi
}

\begin{abstract}
Collaborative learning is advocated because of its pedagogical advantage, which allows knowledge construction through group discussions among learners. In a collaborative learning environment, there will be many learners with diverse cultures. The pedagogical advantages of collaborative learning include learners from different cultural orientation sharing unique learning experiences. The purpose of this study is to investigate learners' experiences in a multicultural remote collaborative learning environment among three countries, South Africa, Kenya and Finland. An Informational and Communication Technology for Development (ICT4D) course was offered to 51 online students from three Universities in the countries mentioned. The course was group-work focused and groups were comprised of students from different Universities. A questionnaire was designed and distributed online to these students. The objective of the questionnaire was to assess students' experiences in a remote collaborative, tools used and knowledge sharing in the course. Research findings indicated that students utilized well synchronous and asynchronous communication technologies but also faced challenges like time differences and unequal contribution and participation in groups. However, team work of the students was excellent owing to the fact that 17 students managed to achieve the goal of the virtual learning for ICT4D course through remote collaborative learning.
\end{abstract}

Keywords: Collaborative learning; Multicultural; Learners' experiences; Universities; ICT4D.

\section{Introduction}

Online collaboration learning is based on constructivist view of learning which requires learners and instructors to work together when solving problems, completing 
tasks, or creating products[1]. Creating online learning communities rich in collaborative learning tasks has been pointed out as of major benefit to adults who can share work related experiences around the globe [2]. In the past, collaborative learning has been restricted to the classroom environment because of the logistical difficulties in distance learning environment [3]. However, with the introduction of internet technologies in Learning Management Systems (LMSs) such as Wiki Spaces, workshops and forums for collaborative work, new opportunities for student collaboration in an online environment have been created[4]. In Computer Supported Collaborative learning different communication tools both video based and text based can be used to provide a platform for the group members to discuss adequately and express their ideas in the desirable form. Text based communication like chats, emails, blogs and forums are widely used to discuss group task in an online collaborative learning environment as they are widely available in most LMSs [5]. However, without other visual communication tools such as Skype, learners may miss facial expressions which are useful to monitor the partner understands of the concept in a remote collaborative learning environment. Therefore, if learners are joining groups in different locations, all types of collaborative tools should be availed.

According to [6] there are seven qualities of learning which are interactive, interrelated, and interdependent with each other. These qualities include:

1. Active: Learners' role in learning process is active; they are engaged in mindful processing of information and they are responsible for the result.

2. Constructive: Learners construct new knowledge on the basis of their previous knowledge.

3. Collaborative: Learners work together in building new knowledge in cooperation with each other and exploiting each other's skills.

4. Intentional: Learners try actively and willingly to achieve a cognitive objective.

5. Contextual: Learning tasks are situated in a meaningful real world tasks or they are introduced through case-based or problem-based real life examples.

6. Transfer: Learners are able to transfer learning from the situations and contexts, where learning has taken place and use their knowledge in other situations.

7. Reflective: Learners articulate what they have learned and reflect on the processes and decisions entailed by the process.

Some of these qualities do assess the collaborative learning aspect while others assess the quality of transfer of knowledge to individual learner. This paper utilizes these qualities of learning to assess the learners' perceived learning qualities on a remote collaborative learning environment.

Collaborative learning is of value in that it enables knowledge sharing and this increases the more diverse the collaborating group. Collaborative learning is even more important in today's environment characterized by factors, such as globalization. In addition, problem solving, for example in industries, is usually multidisciplinary and thus making collaboration a necessity. There are efforts which need to be done, such as understanding students as users of the learning management systems [7], [8]. Recent studies show that online collaborative learning enhances knowledge construction and promotes learner centered learning pedagogy [9], [10]. In multicultural collaborative learning environment, there is a possibility diversity in 
cultural background can bring different ways of reasoning, cooperation skills and social relationship between group members[11]. These differences might influence the quality of collaborative learning and the perceived challenges on a remote collaborative learning environment. Cultural differences among team members should not be under estimated because they can cause conflicts, misunderstanding and poor performance. In addition this, [12] identified the following five typical challenges that are associated with multicultural teams: (i) Managing cultural diversity, differences and conflicts,(ii) Handling geographic distances, dispersion and despair, (iii) Dealing with coordination and control aspects (iv) Maintaining communication richness and (v) Developing and maintaining teamness. However, few empirical studies have analyzed student's experiences on remote collaboration in a multicultural learning environment [13]. In view of this, this study discusses the learners' experiences in learning ICT4D course which was offered online through remote collaboration to students from three different countries.

The Objectives were:

2. To investigate students' experiences on remote collaboration

3. To identify student preferred remote collaborative learning tools

4. To identify challenges and opportunities for offering an online course through remote collaborative environment

5. To identify students' perceptions on the quality of learning experienced through remote collaboration

\section{Research Methodology}

University of Tampere hosted an ICT4D online course in autumn 2016. The course was done in collaboration with University of Venda in South Africa and Kenyatta University in Kenya. The course was team-work focused and students from different universities were put in groups. Most of the course tasks about $80 \%$ were group tasks, so students had to collaborate remotely with students from other universities and submit course tasks.

\subsection{Research Design}

A descriptive survey using three Institutions of Higher Learning (IHL) in three countries was adopted. This research design was applied to investigate students' experience in remote collaborative learning environment. A descriptive survey was adopted as it could examine the situation the way it was and provide quantitative information that can be summarized through statistical analysis, thus providing the basis to answer our research objectives [14]. An online questionnaire was administered using a web-based tool (Google doc) to a group of students who registered ICT4D Course online in the three Universities. This approach was preferred because students are geographically dispersed; it enabled a faster collection of responses and the ease of exporting the data to Statistical Package for Social Sciences (SPSS) for analysis. 


\subsection{Sample and Sampling Procedures}

A purposive sampling was done where the researchers requested students to voluntary register for ICT4D course in three Universities from three different countries. From the target institution the researchers requested the participants to register for the course online within a specific period of time and provide emails to the course cocoordinators. A total of 48 students registered but only 17 students managed to finish the course. Learning materials were availed through Moodle and all participants were required to enroll into Moodle in order to access learning materials.

\subsection{Research Instruments}

Data was collected through a questionnaire that consisted of items to capture student's demographic data, students' experiences in remote collaboration on ICT4D course, students' challenges in remote collaboration and students' perspective on the quality of learning experienced in a remote collaborative learning environment. To ensure validity, content related evidence was adopted and expert analysis was done to review the format and relevance of the items to the research objectives.

\subsection{Data Collection and Analysis}

The web based questionnaire was distributed through email invitations to the participants at the end of the course. The invitation email contained the purpose of the study and a link to the URL where the questionnaire was located. A total of 17 responded which was $100 \%$ for those who finished the course: The collected data was exported to SPSS and coded as per the research objectives. For quantitative data a descriptive analysis was carried out, such as frequencies and percentages on: demographic data, students' experiences in remote collaboration on ICT4D course. For qualitative data narratives based on themes for the students' challenges in remote collaboration and students' perspective on the quality of learning experienced in a remote collaborative learning environment was adopted.

\section{Results}

In this section, we present our results using descriptive statistics for quantitative data and narratives based on themes for the qualitative data.

\subsection{Learner Demographic and Characteristics Information}

The study findings on demographic and characteristics information are presented on Table 1. As shown in Table 1 the majority of the learners were doing masters. 
Table 1. Frequencies on the demographic Information $(\mathrm{N}=17)$

\begin{tabular}{lcc}
\hline Level of Study & Frequency & $\%$ \\
\hline Bachelor & 5 & $29.4 \%$ \\
Master & 8 & $47.1 \%$ \\
PhD & 3 & $17.6 \%$ \\
Other & 1 & $5.9 \%$ \\
\hline
\end{tabular}

\subsection{Students Experiences on the Remote Collaborative Course Environment}

In additional to demographic information, students' experiences on collaborative learning were captured using a 5-point Likert scale from not at all (1) to totally (5), as shown in Table 2.

Table 2. Frequencies on Students experiences on the collaborative course Environment based on 5-point Likert scale

\begin{tabular}{|c|c|c|c|c|c|}
\hline \multirow[t]{2}{*}{ Students Experiences } & \multicolumn{5}{|c|}{ Frequencies } \\
\hline & 1 & 2 & 3 & 4 & 5 \\
\hline $\begin{array}{l}\text { The course environment enabled me to easily contact other } \\
\text { participants }\end{array}$ & 1 & 4 & 5 & 4 & 3 \\
\hline I did not feel lonely in the course environment & 0 & 2 & 3 & 9 & 3 \\
\hline $\begin{array}{l}\text { The course environment enabled me to get a good } \\
\text { impression of other participants }\end{array}$ & 0 & 3 & 7 & 3 & 3 \\
\hline $\begin{array}{l}\text { The course environment allowed spontaneous informal } \\
\text { conversations }\end{array}$ & 3 & 4 & 4 & 3 & 3 \\
\hline $\begin{array}{l}\text { The course environment helped us to develop into a well } \\
\text { performing team }\end{array}$ & 3 & 3 & 4 & 1 & 6 \\
\hline $\begin{array}{l}\text { The course environment enabled us to develop good work } \\
\text { relationships with other participants }\end{array}$ & 3 & 2 & 4 & 4 & 4 \\
\hline $\begin{array}{l}\text { The course environment enabled me to identify myself } \\
\text { with the other participants }\end{array}$ & 0 & 6 & 2 & 6 & 3 \\
\hline I felt comfortable with the course environment & 1 & 2 & 4 & 7 & 3 \\
\hline $\begin{array}{l}\text { The course environment allowed for non-task-related } \\
\text { conversations }\end{array}$ & 4 & 3 & 3 & 6 & 1 \\
\hline $\begin{array}{l}\text { The course environment enabled me to make close } \\
\text { friendship with my team mates or other participants }\end{array}$ & 4 & 3 & 6 & 2 & 2 \\
\hline $\begin{array}{l}\text { How much do you value team/group work in your online } \\
\text { learning experience }\end{array}$ & 0 & 4 & 2 & 7 & 4 \\
\hline
\end{tabular}

Results indicated that most participants were able to link to one another and interact socially.

\subsection{Tools and Methods Used for Remote Collaboration}

Apart from the tools which were availed in Moodle for group work, students were able to interact remotely through Skype, email, whatsapp, Facebook and edit documents remotely using Google drive and Google doc. Table 3 summarizes the remote collaborative tools and how the students utilized them. 
Table 3. Remote collaborative tools used

\begin{tabular}{|c|c|}
\hline $\begin{array}{l}\text { Collaborative } \\
\text { tool }\end{array}$ & Purpose \\
\hline Google Drive & To store data \\
\hline $\begin{array}{l}\text { Google } \\
\text { Doc/slide }\end{array}$ & $\begin{array}{l}\text { Report and presentation for group assignment, online editing shared } \\
\text { documents }\end{array}$ \\
\hline Skype & To discuss and write together \\
\hline email & To contact and discuss group work \\
\hline Whatsapp & To get connected and discuss group work \\
\hline Facebook & To get connected and discuss group work \\
\hline
\end{tabular}

\subsection{Challenges Encountered in Remote Collaboration}

During the remote collaboration participants encountered a number of challenges such as un-equal participation, time difference, lack of face to face interaction, lack of prompt feedback and internet connectivity. Table 4 illustrates some cited examples for the challenges from students’ perspective.

Table 4. Students' challenges in remote collaboration

\begin{tabular}{|c|c|}
\hline Challenges & Cited example \\
\hline $\begin{array}{l}\text { Un-equal } \\
\text { Participation }\end{array}$ & $\begin{array}{l}\text { - Our group (group 5) has not really formed a group for working together. I have } \\
\text { contributed in both assignments but some group members have not really } \\
\text { contributed so much which is in my opinion ok as long everything contributes at } \\
\text { least something. In the first assignment one of us took voluntary lead on the } \\
\text { assignment and in the second one I took the lead in editing contributions. } \\
\text { However, in the second assignment only me and one other person contributed so } \\
\text { the remote group work has not worked } \\
\text { - Some people just faded out from the group - they didnt participate and finally they } \\
\text { left our Skype group. In addition, some people do not participate during the whole } \\
\text { group task - they only participate during the last days and I feel that this is unfair } \\
\text { for the others. So in my opinion, the group work is not working that well and I } \\
\text { wish the amount of group work in this course would be smaller. I also have } \\
\text { personal reasons for this opinion, because I think group work is not the best way } \\
\text { for me to learn things. }\end{array}$ \\
\hline $\begin{array}{l}\text { Time } \\
\text { Difference }\end{array}$ & $\begin{array}{l}\text { - Everyone is in different time zone so it becomes an issue sometimes if instant } \\
\text { feedback is required } \\
\text { - It is hard to get everyone online at the same time so sometimes you have to wait to } \\
\text { hear back from others. Also everyone has their own schedules so when one is } \\
\text { ready some of the others have not yet even started. But it has worked out } \\
\text { surprisingly easily. }\end{array}$ \\
\hline $\begin{array}{l}\text { Lack of face } \\
\text { to face } \\
\text { interaction }\end{array}$ & $\begin{array}{l}\text { - It is hard to get some of group members to do their part of the job, when you don't } \\
\text { see face to face. Someone say that yes they will participate, but in the end, they } \\
\text { haven't done anything. Someone doesn't even respond to your e-mail. Google docs } \\
\text { is a good tool because there you can see who has written which part. }\end{array}$ \\
\hline $\begin{array}{l}\text { Lack of } \\
\text { prompt } \\
\text { feedback }\end{array}$ & $\begin{array}{l}\text { - Lack of communication, and late response } \\
\text { - group members not answering to emails - group members sending personal emails } \\
\text { instead informing the whole group - personal emails with requests such as "I have } \\
\text { no time to contribute to assignment but please add my name to it" - group } \\
\text { members not participating to assignments }\end{array}$ \\
\hline $\begin{array}{l}\text { Internet } \\
\text { Connectivity }\end{array}$ & - Wifi problems from my side so accessing the information on time was a challenge \\
\hline
\end{tabular}




\subsection{Students' Perceptions' on Remote Collaboration for Learning ICT4D Course}

During the group work students were required to actively participate, construct knowledge together, conceptualize concepts and transfer knowledge to one another. In view of this, students were requested to identify among seven qualities of learning, which quality of learning they experienced during the remote collaborative learning. As shown in Table 5, Students perceived that all the qualities were realized with the aspect of collaboration been rated highly (70.6\%).

Table 5. Frequencies and percentages (\%) on Students' perceptions’ on remote collaboration

\begin{tabular}{lll}
\hline Quality of learning & Frequency & $\%$ \\
\hline Active & 10 & 58.8 \\
Constructive & 10 & 58.8 \\
Collaborative & 12 & 70.6 \\
Intentional & 8 & 47.1 \\
Conversational & 10 & 58.8 \\
Contextualized & 7 & 41.2 \\
Reflective & 8 & 47.1 \\
Transfer & 11 & 64.7 \\
None of the above & 2 & 11.8 \\
\hline
\end{tabular}

\section{Discussion}

The composition of the virtual team involved 52 participants from 3 countries where 4 were instructors, namely Kenya (2 instructors, 10 students), Finland (1 team leader, 27 students) and South Africa (1 instructor, 11 students). This formed a multicultural team which [12], defined as a task oriented group consisting of people of different nationalities and cultures. They were positioned in individual, geographically distant countries with participation in the learning process being virtual.

Collaborative learning experience in the ICT4D course had other dimensions besides academic aspect as demonstrated in Table 2, for example, social and knowledge sharing [16]. The social aspect of online learning has been emphasized as important to reduce loneliness in past research[17]. Loneliness in online learning is one of the reasons of high dropout rate. Therefore, group-work is one way of reducing loneliness by encouraging interaction in the groups. Knowledge sharing was a big component of this collaborative learning experience because of the diverse cultural background of the students. For example one student commented:

"it's a wonderful learning platform that allow for interactions of people even when they are far from each other"

Regarding to remote communication as illustrated in Table 3 students were able to utilize both asynchronous and synchronous communication tools to share ideas and collaborate remotely. There were also challenges that were witnessed during the collaboration experience as demonstrated in Table 4. For example, in some groups not all the students participated well and contributed to the academic tasks. This made the workload much heavy on the other participants thus making it unequal distribution of 
the tasks but at the end, all the students in the group had the same grade. Another challenge was limited internet access for some students, which limited their contribution and hindered synchronous group communication. Despite these challenges, students appreciated the remote collaborative learning environment as it enabled them to realize some of the qualities of learning as illustrated in Table 5.

\section{Conclusion and Future Work}

The Remote collaborative learning for ICT4D Course allowed the students to develop shared culture that played a role in relationship building as groups virtually. Team work of the students was excellent owing to the fact that 17 students with the assistance of instructors managed to achieve the goal of the virtual learning for ICT4D course through remote collaboration. This was a step towards building and maintaining personal relationships of the participants virtually whilst ensuring that individuals developed commitment which enabled working towards achieving a common goal.

Collaborative learning opens up new avenues in the students' learning experience. It enables students' to learn about other cultures and thus broaden the understanding of different cultures. The experience in this course, with students from Kenya, South Africa and Finland offered such possibility. This collaborative learning experience is more challenging that the typical classroom learning experience. The challenges are worthy it in that it helps develop both academic and personal attributes of students. Understanding these challenges would help instructors to develop mechanisms which can address them and make remote collaborative learning more effective, appealing and satisfactory to students.

\section{References}

[1] E. M. Maina, P. W. Wagacha, and R. Oboko, “A Model for Improving Online Collaborative Learning through Machine Learning,” Model. Improv. Optim. Online Blended Learn. High. Educ., pp. 204-219, (2014).

[2] C. J. Bonk and V. Dennen, "Teaching on the Web: With a little help from my pedagogical friends,” J. Comput. High. Educ., vol. 11, no. 1, pp. 3-28, (1999).

[3] L. Kimball, "The Digital University: Reinventing the Academy,” R. Hazemi, S. Hailes, and S. Wilbur, Eds. Berlin, Germany: Springer Verlag, pp. 25-38, (2001).

[4] R. Gitonga, M. Muuro, and D. Nzuki, "Students experiences of using Wiki spaces to support collaborative learning in a blended classroom: A case of Kenyatta and KCA universities in Kenya,” in IST-Africa Conference Proceedings, pp. 1-10,(2014).

[5] E. Muuro, P. Wagacha, R.Oboko, and J. M. Kihoro, “Students' Perceived Challenges in an Online Collaborative Learning Environment: A Case of Higher Learning Institutions in Nairobi, Kenya,” Int. Rev. Res. Open Distance Learn., vol. 15, (2014).

[6] H. Ruokamo and S. Pohjolainen, "Pedagogical principles for evaluation of hypermedia-based learning environments in mathematics,” J. Univers. Comput. Sci., vol. 4, no. 3, pp. 292-307, (1998).

[7] N. Mavengere and M. Ruohonen, "ICT4D 2.0 studies in virtual environment: Context and user needs to foster learning process,” in IST-Africa Week Conference, pp. 1-8, (2016). 
[8] D. E. Leidner and S. L. Jarvenpaa, "The use of information technology to enhance management school education: A theoretical view,” MIS Q., pp. 265-291, (1995).

[9] M. E. Muuro, R. O. Oboko, and P. W. Wagacha, "Evaluation of Intelligent Grouping Based on Learners Learning Environment,” Int. Rev. Res. Open Distrib. Learn., vol. 17, no. 2, (2016).

[10] E. M. Maina, P. W. Wagacha, and R. Oboko, "Enhancing Active Learning Pedagogy through Online Collaborative Learning,” Handb. Res. Act. Learn. Flip. Classr. Model Digit. Age, p. 232, (2015).

[11] T. Baker and J. Clark, "Cooperative learning--a double-edged sword: a cooperative learning model for use with diverse student groups,” Intercult. Educ., vol. 21, no. 3, pp. 257-268, (2010).

[12] M. J. Marquardt and L. Horvath, Global teams: How top multinationals span boundaries and cultures with high-speed teamwork. Nicholas Brealey Publishing, (2001).

[13] C. Zhu, “Online collaborative learning: Cultural differences in student satisfaction and performance/Kulturelle Unterschiede in der Zufriedenheit mit und den Lernertr\{ä\}gen aus online-gest $\{\ddot{u}\}$ tztem kollaborativem Lernen bei Studierenden,” J. Educ. Res. online, vol. 3, no. 1, p. 12, (2011).

[14] J. R. Fraenkel, N. E. Wallen, and H. H. Hyun, How to design and evaluate research in education. New York, N.Y: McGraw-Hill Higher Education, (2012).

[15] L. R. Frey, D. Gouran, and M. S. Poole, The handbook of group communication theory and research. Sage, (1999).

[16] K. Illeris, How we learn: Learning and non-learning in school and beyond. Routledge, (2007).

[17] K. Kreijns, P. A. Kirschner, W. Jochems, and H. Van Buuren, "Measuring perceived sociability of computer-supported collaborative learning environments," Comput. Educ., vol. 49, no. 2, pp. 176-192, (2007). 